\title{
Design of DC-DC Buck Converter for Smartphone Applications Based on FPGA Digital Voltage Controller
}

\author{
Mustafa M. Salih ${ }^{1}$, Ahmed S. Al-Araji ${ }^{2}$, and Hassan A. Jeiad ${ }^{3}$ \\ ${ }^{1,2,3}$ Computer Engineering Department, University of Technology, Baghdad, Iraq \\ 120630@student.uotechnology.edu.iq,60166@uotechnology.edu.iq,120004@uotechnology.edu.iq
}

\begin{abstract}
This paper presents an enhancement of the output performance of a linear buck converter system for the mobile (smartphone) devices using an adaptive digital ProportionalIntegral-Derivative (PID) controller with off-line swarm optimization algorithm. The work focuses on improving the use of using single-input single-output (SISO) digital Field Programmable Gate Array (FPGA)-PID to control the linear buck converter system. The goal of the proposed adaptive SISO-FPGA-PID voltage-tracking controller is to rapidly and precisely identify the optimal voltage control action (optimal on-off duration time) that is used to control the buck converter output voltage level in order to avoid the troubleshooting hardware problem issues on mobile devices. The Particle Swarm Optimization (PSO) algorithms are used to find and tune the three weights of the SISO-FPGA-PID controller. The numerical simulation results and the experimental work using Spartan-3E xc3s500e-4fg320 board with Verilog hardware description language (HDL) show that the proposed controller is more accurate in terms of voltage error and the number of function evolutions are of high reduction. As well as to generate a smooth voltage control response without voltage oscillation in the output by investigating under mobile applications variations such as using Bluetooth, WI-FI, and CPU operating voltage when these results are compared with other controllers.
\end{abstract}

Index Terms-Buck Converter System; Adaptive SISO-FPGA-PID Controller; Off-Line Particle Swarm Optimization.

\section{INTRODUCTION}

Mobile clients spend larger part of their time utilizing the mobile applications (apps). These mobile applications are designed and allocated for internet access, communications, scheduling, data transferring, entertainment and many more applications that make the smartphones critical and essential in users' dayto-day activities. Many different mobile applications are designed to be able to be accessed and used by mobile user simultaneously. Moreover, the usefulness and complexity of the mobile apps require more resources from the mobile phone. These involve higher CPU utilization, more memory utilization and speedier wireless communication radio, [1]. These applications consist of software and hardware. Thus, for viable utilization of mobile devices distinctive applications ought to be with enhanced and fully optimized performance in terms of quickly power delivered and keeping on precisely voltage level during using these applications, in order to avoid the troubleshooting hardware problem issues on mobile devices. In this way, designing and controlling the switching circuits for "DC-DC power converter" responsible for the battery operation are needed to attain the regulation of voltage for quick transient response with high efficiency of conversion, [2]. The DC-DC converters are the most power electronic circuit that changes main sources of direct current (DC) from one voltage level to another voltage level by switching activity. This will be done by altering the duty cycle of the main switches within the control circuits. The switches are active transistors. These converters are a generally utilized as regulated switched mode power supplies, which converts the unregulated DC input to a regulated DC output, [3]. 
The control and stabilization of switching converters are the essential factors that ought to be a considered. Therefore, the motivation of this work is appropriate control strategy must bargain with the dynamic behavior dilemmas of DC-DC converters, which influence the work of mobile devices. These dilemmas are epitomized by the variation in the output voltages; the wide scale of loading current; uncertain model parameters and the levels variation in input voltage, [2], [4].

In the related literature, numerous researchers exploit robust control methodologies in order to keep up with the demanded control objectives. In this context, the predictive controller to ensure a tight regulation of the output voltage that led to stabilize the buck converter output was suggested in [5]. The PI-Lead controller is used to regulate the output voltage of buck converter through tuning the parameters of controller in two parts, PI part enhance the steady state response and Lead part enhance the transient response of unregulated system that was proposed in [6]. In addition, the studied Hysteresis Controller was proposed in [7] to achieve the required fast transient control unit, which enabled the controller to respond to the output voltage deviation rapidly and to control the timing of the bandwidth adjustment. Also, the back-stepping controller by depending on the dynamical model of buck converter in order to provide good robustness against outer disturbances and improve the performance of rapidly tracking to the output voltage response was presented in [8]. The exhibited fuzzy logic controller to achieve a stable and fast speed response of the buck converter system through evaluating and obtaining best control action as pulse width modulation (PWM) and altering continuously duty cycle until reaching the desired output voltage without a need to the buck converter mathematical model was explained in [9]. Furthermore, the sliding mode controller that achieved the stability and robustness of the system parameters in the presence of unexpected load and input voltage variations with constant frequency was proposed in [10].

This paper focuses on optimizing the dynamic responses of the buck converter output voltage and stabilizing its power output, particularly when different loads are employed in mobile applications. However, representative modelling of the buck converter system and control of the output voltage remain challenging issues. This paper provides the following:

- An analysis of the buck converter operating system with respect to the effect of each variable parameters, such as capacitor resistor, indictor resistor and the load current.

- A feedback SISO-PID controller is designed for the use in stabilizing and tracking the desired output voltage of the buck converter system in a transient state with variable Smartphone applications such as Bluetooth, Wi-Fi, as well as CPU operating voltage, in addition to obtaining optimal (or near optimal) voltage control action using off-line tuning swarm algorithm.

- A digital SISO-FPGA-PID control law is designed, implemented and verified using a FPGA Spartan3E Starter kit xc3s500e-4fg320 device with Verilog hardware description language in real-time MATLAB environment system.

This paper is arranged as follows: Section 2 explains the modelling of the buck converter system; Section 3 presents the SISO-FPGA-PID controller using off-line particle swarm optimization algorithm; Section 4 discusses the numerical results of simulations conducted using the proposed controller; Section 5 demonstrates the experimental work based on Spartan 3E Starter kit; and Section 6 gives conclusions made with respect to the proposed controller.

\section{BUCK CONVERTER MATHEMATICAL MODEL}

The DC-DC Buck converter can be classified into the Step down or Chopper circuits. In fact, the output voltage (Vo) of the buck converter is less than input voltage source $(\mathrm{Vg})$, because the input voltage source $(\mathrm{Vg})$ is stepping down through the factor $(\Delta)$, [11]. Having a precise and complete model, which contains all the system parameters (such as the active switch turn-on resistance, inductor and capacitor resistance) is the main step in designing a non-conservative robust controller for Buck convertors. So that in this work, all parasitic resistance of elements are considered in order to obtain more accurate model, [12]. As shown 
in Fig. 1, the buck converter circuit consists of two active n-channel MOSFETs power (Q1) for switch and (Q2) for synchronous rectifier, main inductor $(\mathrm{L})$, main capacitor $(\mathrm{C})$, load resistance $(\mathrm{R})$, input voltage source $(\mathrm{Vg})$, output voltage $(\mathrm{Vo})$, capacitor voltage $(\mathrm{Vc})$, and inductor voltage $(\mathrm{VL})$.

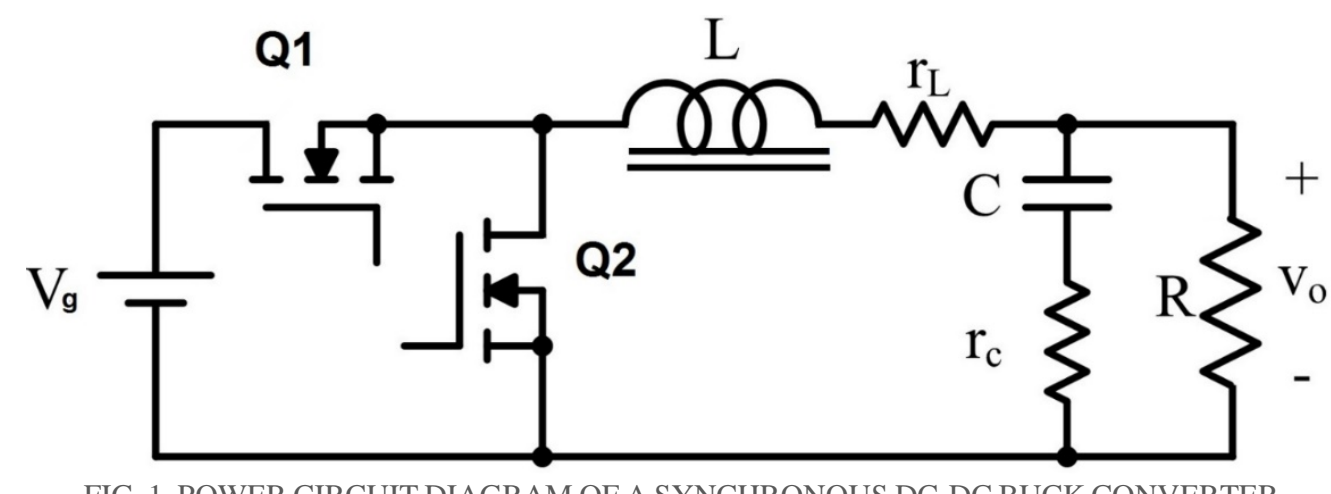

FIG. 1. POWER CIRCUIT DIAGRAM OF A SYNCHRONOUS DC-DC BUCK CONVERTER.

- In circuit of Fig. 1, there are two states; the ON and OFF time states. The on time is indicated by $\Delta \mathrm{T}=\mathrm{T} 1$, and the off time is indicated by $(1-\Delta) \mathrm{T}=\mathrm{T} 2$, where $\mathrm{T}=\mathrm{T} 1+\mathrm{T} 2$.

- During On State when Q1 is on and Q2 is off, at a time period t<T1, and by applying Kirchhoff's voltage law, the circuit analysis can be described as follows:

$V_{g}-i_{L} \cdot r s_{o n}-\mathrm{L} \frac{d i_{L}}{d t}-i_{L} \cdot r_{L}-V_{o}=0$

- During OFF State when Q1 is off and Q2 is on, at a time period $\mathrm{T} 1<\mathrm{t}<\mathrm{T} 2$, and by applying Kirchhoff's voltage law the circuit analysis can be described as follows:

$-i_{L} \cdot r s_{o n}-\mathrm{L} \frac{d i_{L}}{d t}-i_{L} \cdot r_{L}-V_{o}=0$

By defining $\Delta$ as in (3). Which turns ( $V_{g}$ ) on-off as switching function.

$\Delta=\left[\begin{array}{lll}o & \text { to } & 1\end{array}\right]$

Then (1) will be as follows:

$\Delta V_{g}-i_{L} \cdot r s_{o n}-\mathrm{L} \frac{d i_{L}}{d t}-i_{L} \cdot r_{L}-V_{o}=0$

Therefore, (2) and (4) are formed in state space representation as follows:

Let $x_{1}=i_{L}$ then $\dot{X}_{1}=\frac{d i_{L}}{d t}, x_{2}=V_{o}$ then $\dot{X}_{2}=\frac{d v_{o}}{d t}$

$\dot{X}=A . X+B \cdot V_{g} \quad, Y=C . X$

$A=\left[\begin{array}{ll}a_{11} & a_{12} \\ a_{21} & a_{22}\end{array}\right]=\left[\begin{array}{cc}\frac{-\left(r s_{o n}+r l\right)}{L} & -\frac{1}{L} \\ \frac{L R-C R r c\left(r s_{o n}+r l\right)}{L C(R+r c)} & \frac{-C R r c-L}{L C(R+r c)}\end{array}\right]$

$B=\left[b_{1} b_{2}\right]=\left[\frac{\Delta}{L} \frac{R r c}{L(R+r c)}\right] \cdot V_{g}$

$C=\left[\begin{array}{ll}0 & 1\end{array}\right]$

Finally, the continuous-time transfer function of the buck converter model can be expressed as follows:

$\frac{Y(s)}{(s)}=V_{g} \frac{\frac{R r c}{L(R+r c)} S+\frac{R}{L c(R+r c)}}{s^{2}+\left(\frac{r S_{o n}+r l}{L}+\frac{L+C R r c}{L C(R+r c)}\right) s+\frac{R+r s_{o n}+r l}{L C(R+r c)}}$ 


\section{An ADAPTIVE SISO-FPGA-PID CONTROLLER DESIGN}

The control methods such as proportional integral derivative (PID) and algorithms are one of the most important types of effective feedback controllers, which are utilized in many industrial automatic control processes. PID controller has been vastly used in numerous different scopes, such as mechatronics, power systems, drives control, process control, aerospace, and robotics, [13], [14]. PID controller has time domain regulation and good closed loop response, [15]. Fig. 2 illustrates the block diagram of suggested adaptive SISO-PID controller based off-line self-tuning control algorithm, which has a big dynamic characteristic, high adaptation and rugged "robustness" performance because of its capability in tuning and finding the control gains of PID controller.

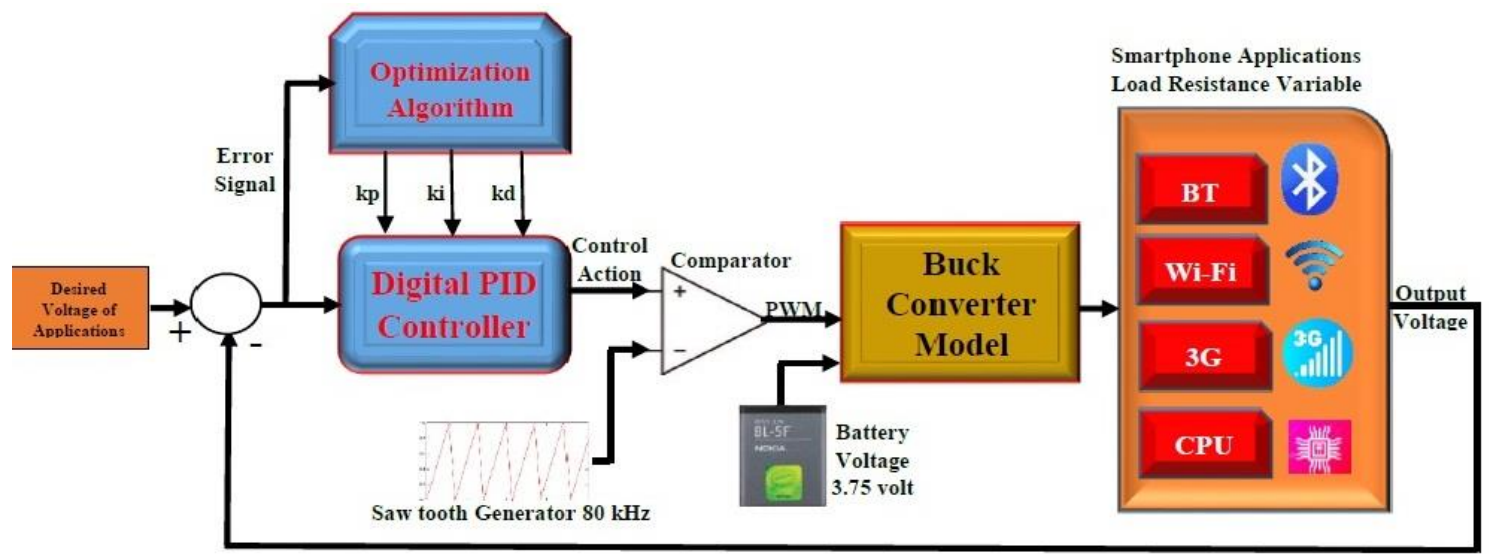

FIG. 2. AN ADAPTIVE DIGITAL SISO-PID CONTROLLER BLOCK DIAGRAM FOR BUCK CONVERTER OF SMARTPHONE APPLICATIONS.

The control operation U(s) of the suggested "off-line self-tuning adaptive PID controller" is very essential for stabilizing the error voltage signal $\mathrm{E}(\mathrm{s})$ for the output of buck converter system to avoid the eroding of output voltage $\mathrm{Y}(\mathrm{s})$ from the offset voltage $\mathrm{Vd}(\mathrm{s})$ and to satisfy a great rating of performance for disturbance repudiation and ambiguous parameters. From [6], the time-domain form of PID controller written as follows:

$\mathrm{u}(\mathrm{t})=K_{p} e(t)+K_{i} \int_{0}^{t} e(t) d(t)+K_{d} \frac{d e(t)}{d t}$

The continuous controller (PID) in (11) is transformed to digital equivalent form as in (12) by using ztransform for implementing the adaptive PID controller in field programmable gate arrays (FPGA), where the integration and differentiation are implemented numerically with backward difference respectively.

$U(z)=\left[K_{p}+\frac{K_{i} T_{s}}{1} \frac{1}{1-z^{-1}}+K_{d} \frac{1-Z^{-1}}{T_{s}}\right] E(z)$

Where: $T_{S}$ is the sampling time at the $k^{\text {th }}$ samples.

Moreover, the effective output $u(k)$ of the controller, described as follows:

$u(k)=u(k-1)+K_{p}(e(k)-e(k-1))+K_{i} e(k)+K_{d}(e(k)-2 e(k-1)+e(k-2))$

Then converting the (13) to a Verilog Hardware Description Language (HDL) program by using Integrated System Environment (ISE) package version 14.7 and it has taken an image to the Verilog program as in Fig. 3. Then using ISim simulator based on ISE package for simulation and testing the SISO-FPGA-PID controller program is verified as shown in Fig. 4. 


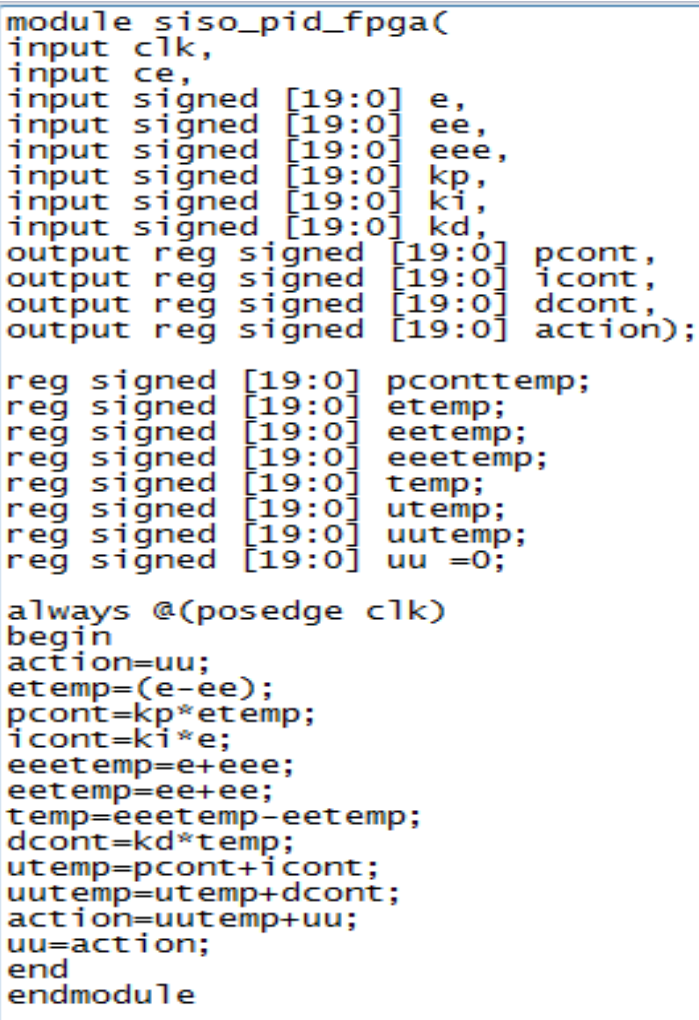

FIG. 3. SISO-FPGA-PID VERILOG PROGRAM AFTER HAS TAKEN IMAGE FOR IT.

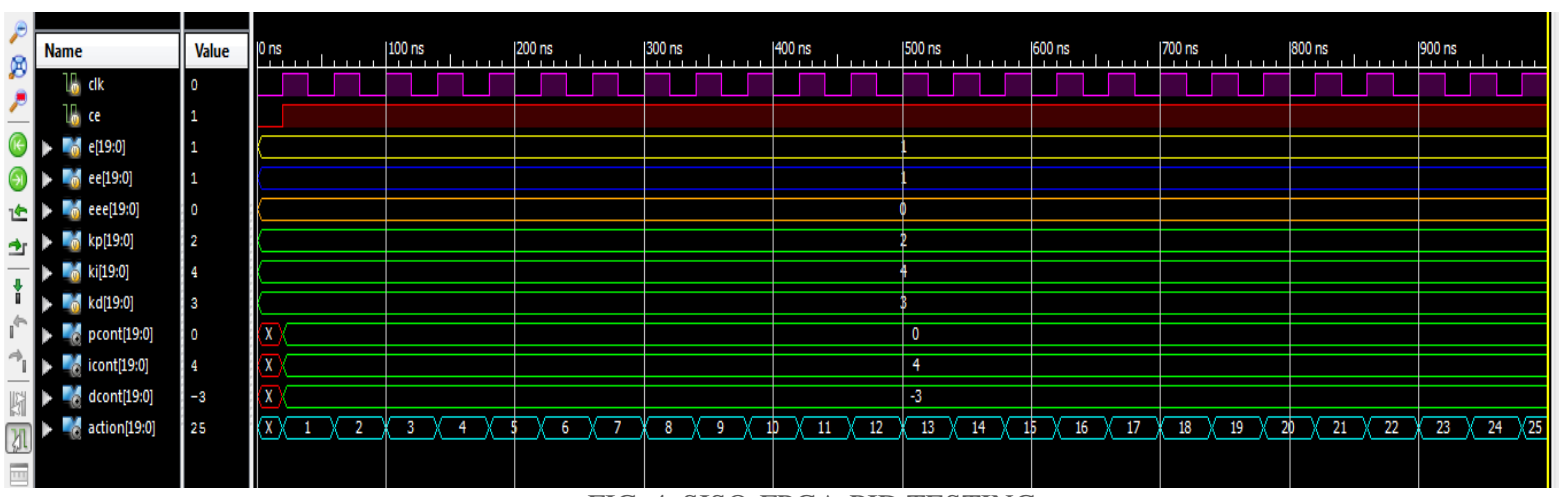

FIG. 4. SISO-FPGA-PID TESTING.

The intelligent off-line PSO algorithm is described in flowchart as shown in Fig. 5 that is used to illustrate the effectiveness of the algorithm in terms of the number of iterations employed, rating the fitness function and obtaining the minimum value for the cost function. These effectiveness lead to find and tune the best weights of the SISO-FPGA-PID controller to produce the good and pure voltage control operation that leads to fast track the desired output voltage of buck converter during load current variation when different application are used. 


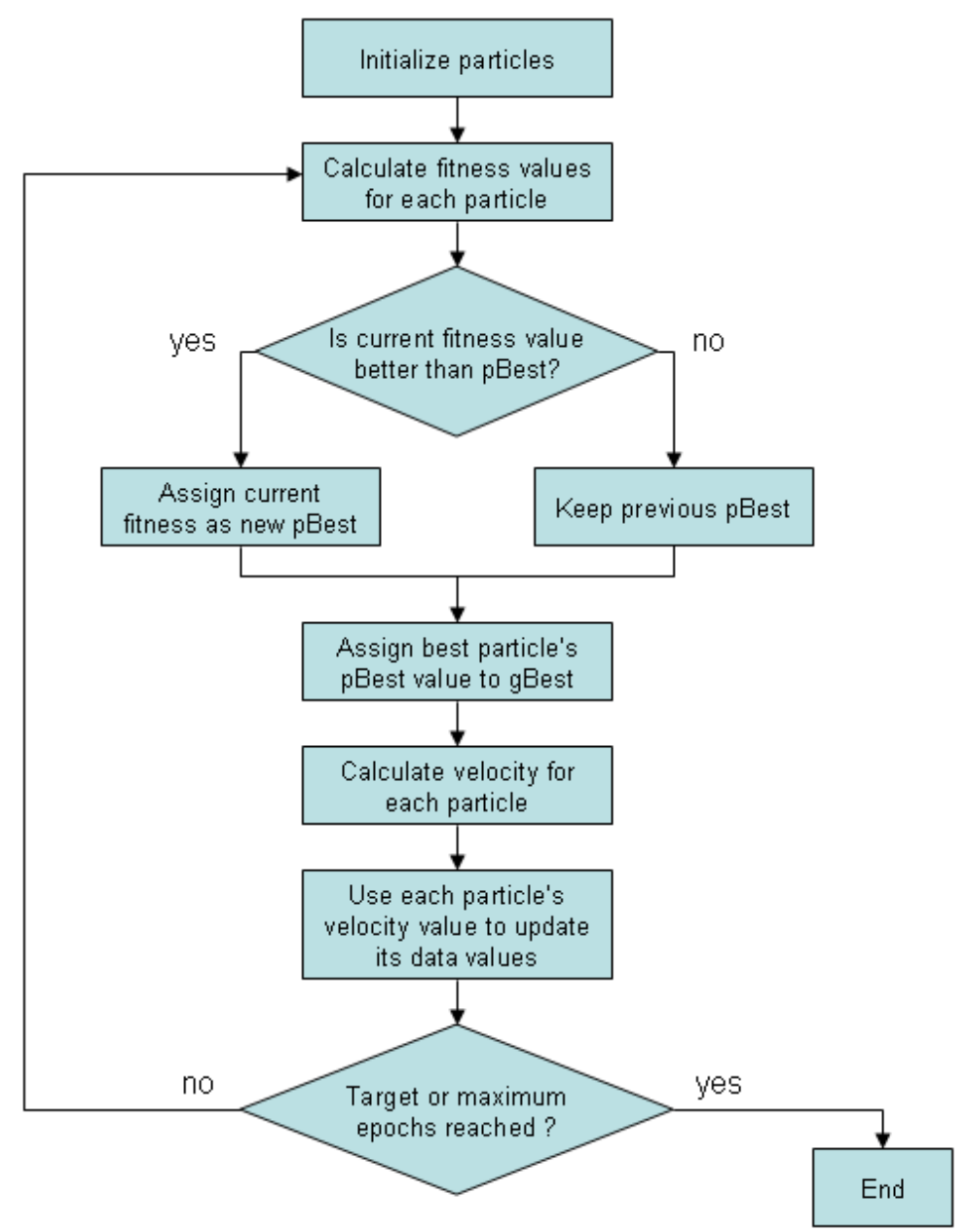

Fig. 5. FLOWCHART OF THE OFF-LINE PSO ALGORITHM.

The particle updates its velocity and positions with following equations: (14) and (15), which are obtained from [16], [17].

$v=w \cdot v+c_{1} \cdot r_{1} \cdot\left(l_{-b e s t}-y\right)+c_{2} \cdot r_{2}\left(g_{-b e s t}-y\right)$

$y=y+v$

Where, $w$ is the inertia weighting factor for the velocity $v ; c_{1}$ and $c_{2}$ are acceleration parameters and positive constants values; $r_{1}$ and $r_{2}$ are random values between 0 and $1 ; l_{-b e s t}$ represents the best previous position visited by each individual particle and $g_{-b e s t}$ represents the position of the best point in search space visited by all swarm particles at yet.

The learning swarm algorithm usually based on minimization of the following off-line cost function,

$\left.E=\frac{1}{P} \sum_{i=1}^{p}[\operatorname{Vdes}(k+1)-\operatorname{Vo}(k+1))^{2}\right]$

Where, $p$ represents the number of training points in the training set; $V o(k+1)$ is the actual output voltage of the buck converter of each $\mathrm{k}^{\text {th }}$ iterations $\operatorname{Vdes}(k+1)$ represents the desired output voltage of every iteration.

\section{MATLAB SIMULATION RESULTS}

In this work, to carry out the proposed controller, the specifications of buck converter power circuit at switching frequency $80 \mathrm{kHz}$ are obtained from, [2] and [18] as illustrated in Table 1. 
TABLE 1. ELECTRONICS COMPONENTS VALUES OF THE BUCK CONVERTER MODEL AT SWITCHING FREQUENCY 80 KHZ [2], [18].

\begin{tabular}{|c|c|c|c|}
\hline Description & Symbol & Value & Unit \\
\hline Inductance & $\mathrm{L}$ & 47 & $\mu \mathrm{H}$ \\
\hline Capacitor & $\mathrm{C}$ & 68 & $\Omega$ \\
\hline Load Resistance & $R_{\text {load }}$ & 2.345 & $\Omega$ \\
\hline $\begin{array}{c}\text { Inductor Effective } \\
\text { Series Resistance }\end{array}$ & $r_{l}$ & 0.13 & $\mathrm{~m} \Omega$ \\
\hline $\begin{array}{c}\text { Capacitor Effective } \\
\text { Series Resistance }\end{array}$ & $r_{c}$ & 55 & $\Omega$ \\
\hline $\begin{array}{c}\text { The ON-n-Channel } \\
\text { Resistance of MOS } \\
\text { Transistors }\end{array}$ & $r s_{\text {on }}$ & 2.1 & $\mathrm{~V}$ \\
\hline \begin{tabular}{c} 
Supply voltage \\
\hline
\end{tabular}
\end{tabular}

Using MATLAB simulation (m.file) to implement the control algorithm PSO tuning with adaptive PID controller in off-line mode, to track the required voltage level in output of the DC-DC buck converter and at specific sampling time. From (10), the natural frequency $W_{n}=2.44 \times 10^{4} \mathrm{rad} / \mathrm{sec}$ and the damping ratio $\zeta=$ 1.12 of the buck converter model can be calculated, from this calculated two values the model time constant which is equal to $\tau=36.5 \mu \mathrm{sec}$ can be calculated and by depending on Shannon's theorem the sampling time can be calculated which is equal to $3.6 \mu \mathrm{sec}$. The specifications in TABLE 1 are represented as difference equation as in (17).

$v_{o}(k)=0.02067 u(k-1)-0.007375 u(k-2)+1.814 v_{o}(k-1)-0.8212 v_{o}(k-2)$

Fig. 6. shows the dynamical behavior of the buck converter output voltage for unit step change open loop response, which has stable response, but it has high voltage error.

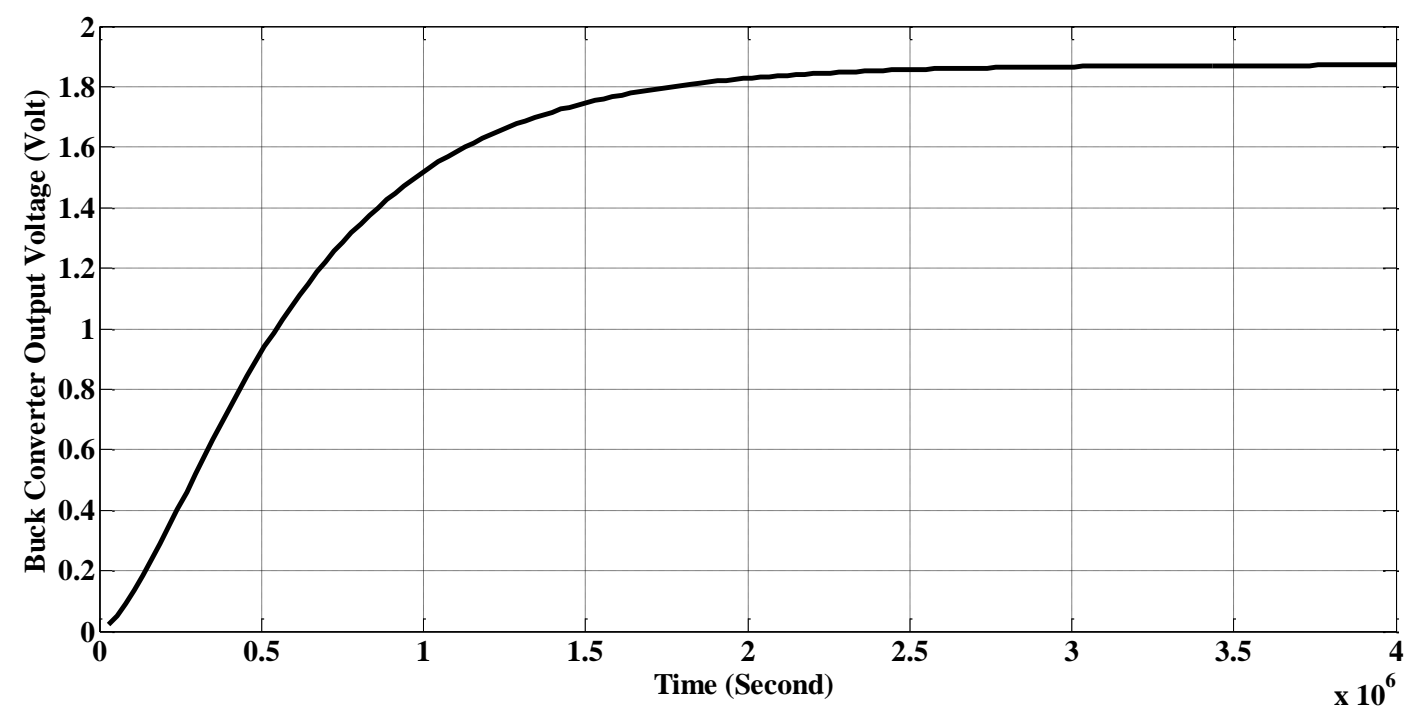

FIG. 6. OPEN LOOP RESPONSE FOR BUCK CONVERTER SYSTEM.

Based on Fig. 2, this is so to demonstrate the adaptive digital SISO-PID controller with off-line PSO tuning control parameters algorithm, which is defined as in, Table 2 . The tuning swarm algorithm and at least number of iterations has the ability to fast producing perfect and pure voltage control operation and reducing the error in the actual output voltage. 
TABLE 2. THE SUGGESTED TUNING PARAMETER VALUES OF ALGORITHM.

\begin{tabular}{|c|c|}
\hline Parameter & Value \\
\hline No. of particles. & 20 \\
\hline Max iteration No. & 50 \\
\hline Acceleration constants, $c_{1}, c_{2}$ & $1.49,1.49$ \\
\hline Random No. $r_{1}, r_{2}$ & {$[0,1]$} \\
\hline Inertia weight, $w$ & 0.73 \\
\hline
\end{tabular}

The specifications of smartphone applications for NoKia N95 that are taken from [19] can be demonstrated in Table 3. to show the equivalent resistance of each application that is represented as variable load at in buck converter output model.

TABLE 3. THE SPECIFICATIONS OF SMARTPHONE APPLICATIONS FOR NOKIA N95 [19].

\begin{tabular}{|c|c|c|c|}
\hline Application & $\begin{array}{c}\text { TTL low Level } \\
\text { Voltage }(\mathrm{V})\end{array}$ & $\begin{array}{c}\text { Full Current load }(\mathrm{mA}) \text { And } \\
\text { Consumption Power }(\mathrm{mW})\end{array}$ & $\begin{array}{c}\text { Equivalent Resistance } \\
(\Omega)\end{array}$ \\
\hline CPU & 1.5 & $408 \mathrm{~mA}, 612 \mathrm{~mW}$ & 3.676 \\
\hline Wi-Fi & 2.5 & $580 \mathrm{~mA}, 1450 \mathrm{~mW}$ & 14.31 \\
\hline Blue Tooth (BT) & 2.5 & $172.8 \mathrm{~mA}, 432 \mathrm{~mW}$ & 14.46 \\
\hline
\end{tabular}

\section{Case I}

The difference equation of buck converter model for CPU application in the smartphone can be represented in Eq. (18).

$v_{o}(k)=0.02092 u(k-1)-0.007459 u(k-2)+1.822 v_{o}(k-1)-0.8277 v_{o}(k-2)$

Figs. 7-a, b, c, d. show the numerical simulation results of the closed-loop digital PID voltage control system with desired voltage step is equal to $1.5 \mathrm{~V}$ for the CPU in the smartphone. Based on off-line PSO algorithm parameters, after finishing 50 iterations, the best control gains parameters are obtained as $\mathrm{kp}=15.5796, \mathrm{ki}=3.2035$ and $\mathrm{kd}=0.8358$. In Fig. 7-a. the output voltage response of the buck converter system was very small over-shoot in the transient state while the error voltage at steady state was equal to zero. In Fig. 7-b. the voltage error signal of the closed-loop buck converter controller system was a small value in the transient and it has become zero at the steady state. In Fig. 7-c. the action response of the digital PID controller was smooth without oscillation response, no spikes behavior and the action did not reach to the saturation state of 3.7 volt depending on the supply voltage. Fig. 7-d. clearly shows the improved performance index of the buck converter system related with the MSE for the off-line tuning PSO control methodology.

(a)

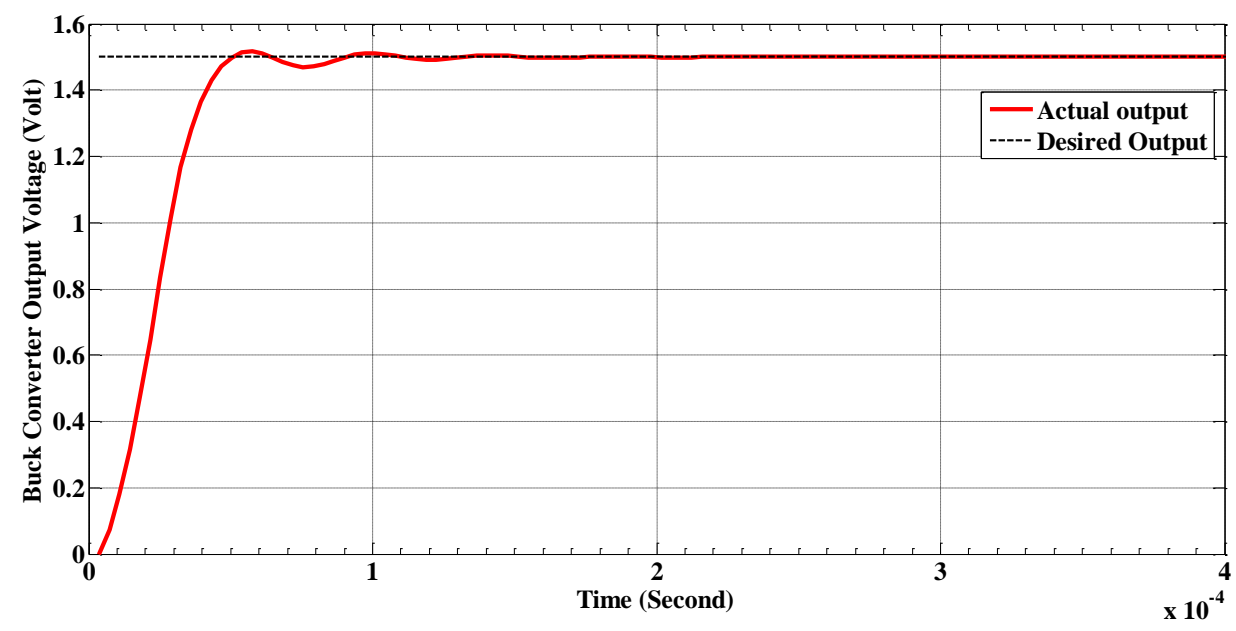


(b)

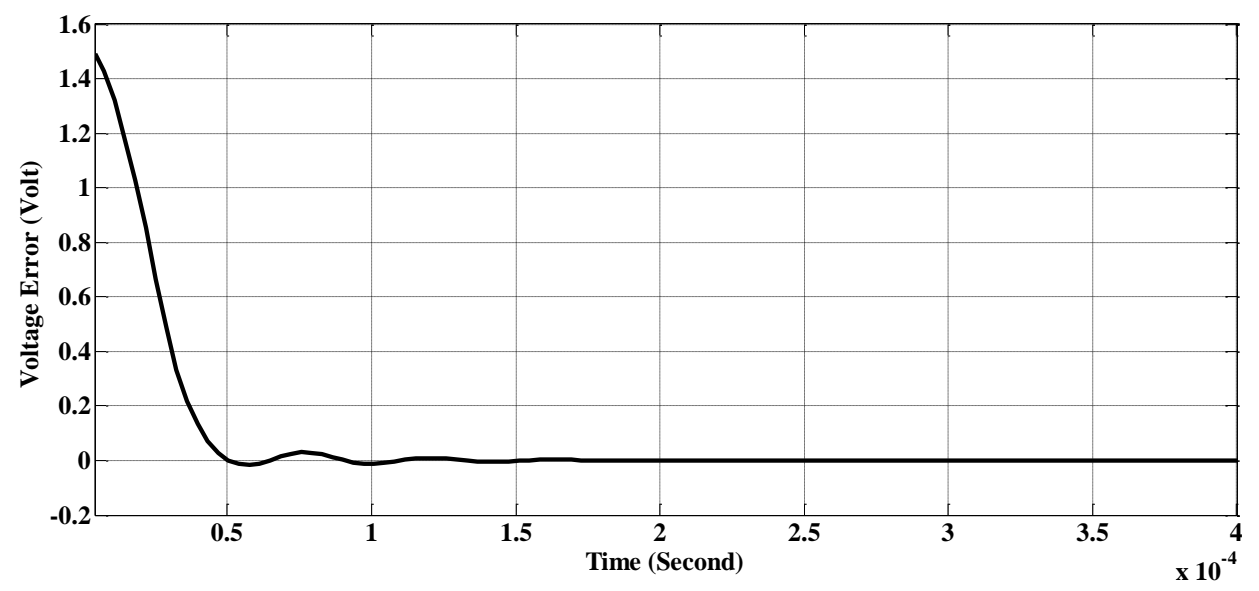

(c)

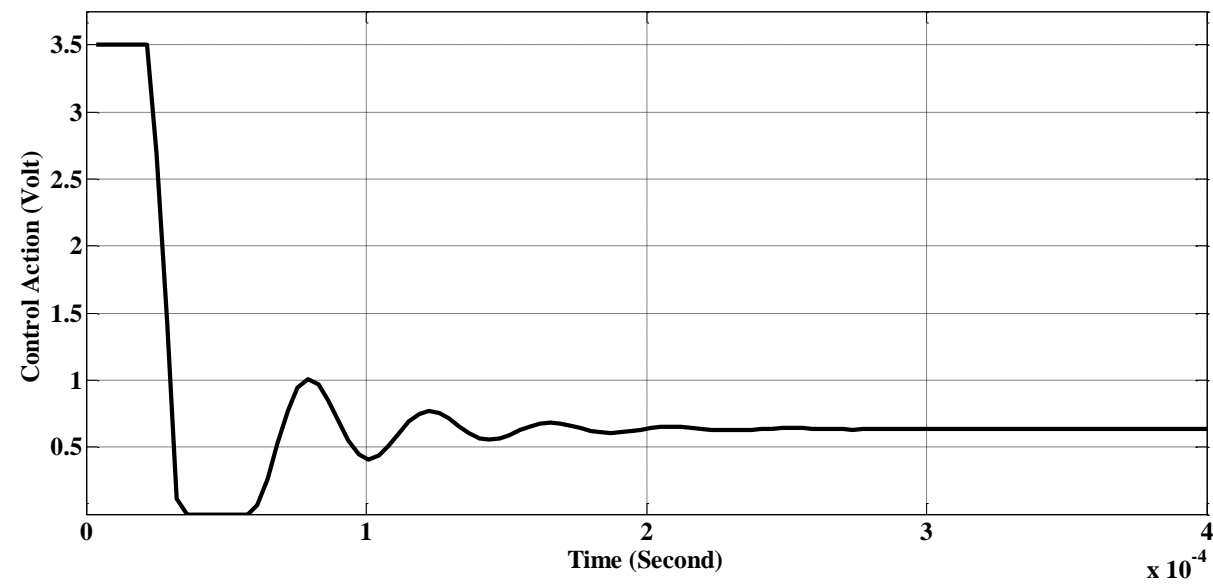

(d)

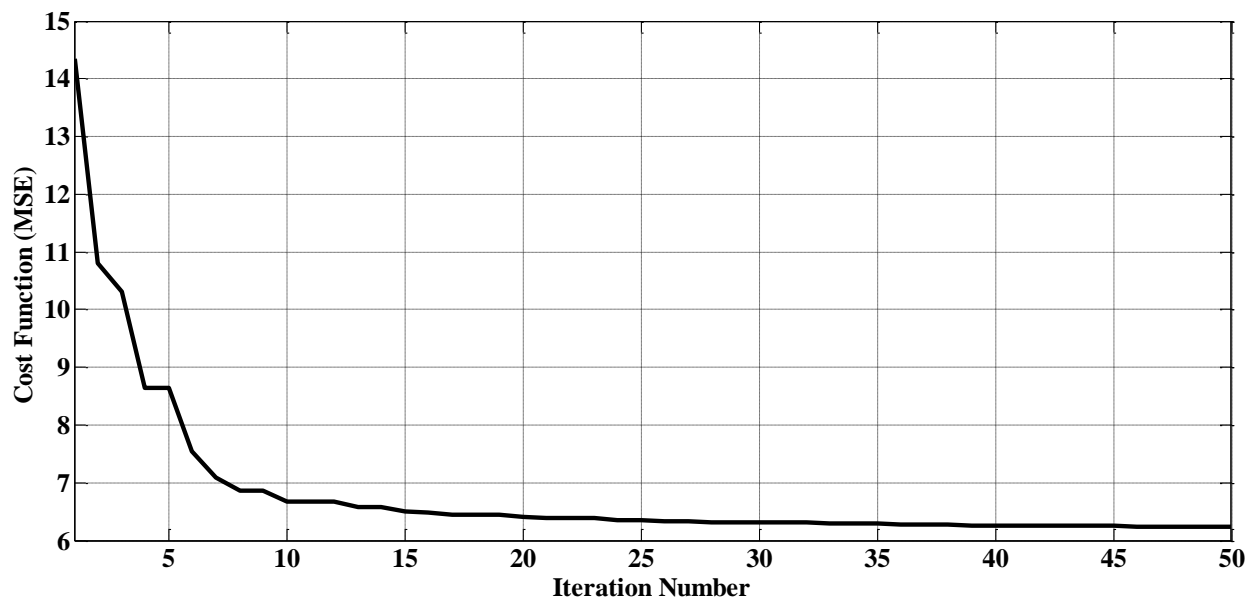

Fig. 7. THE DigITAL SISO-PID CONTROLLER NUMERICAL SiMULATION RESUltS: (A) BUCK CONVERTER ACTUAL AND DESIRED OUTPUT VOLTAGE; (B) SigNAL ERROR; (C) SignAl CONTROL OPERATION; (D) OFF-LINE PERFORMANCE INDEX (MSE).

The results of the proposed controller are compared with other types of controller results such as [18]; [2]; [20] as shown in Table 4.

TABLE 4. COMPARISON BETWEEN DIFFERENT TYPES OF CONTROLLER.

\begin{tabular}{|c|c|c|c|c|}
\hline Type of controller & Over shoots & Steady-State Error & No. of Iterations & No. of Weights \\
\hline MENN-PID [18] & $2.3 \%$ & 0.0 & 250 off-line & 4 \\
\hline PID [2] & $2.5 \%$ & 0.0 & 600 on-line & 3 \\
\hline Fuzzy-like PID [20] & $4.8 \%$ & Small Oscillation & non & 47 Fuzzy rules \\
\hline Proposed Controller & $1.8 \%$ & 0.0 & 50 off-line & 3 \\
\hline
\end{tabular}




\section{Case II}

The difference equation of buck converter model for Wi-Fi application can be represented as in (19). $v_{o}(k)=0.02098 u(k-1)-0.007481 u(k-2)+1.824 v_{o}(k-1)-0.8293 v_{o}(k-2)$

Figs. 8-a, b, c, d. show that the numerical simulation results of the closed-loop digital PID voltage control system with desired voltage step is equal to $2.5 \mathrm{~V}$ in order to tune on $\mathrm{Wi}-\mathrm{Fi}$ application in the smartphone. Based on off-line PSO algorithm parameters, after finishing 50 iterations, the best control gains parameters are obtained as $\mathrm{kp}=8.6038, \mathrm{ki}=1.6646$ and $\mathrm{kd}=1.0662$. In Fig. 8 -a. the output voltage response of the buck converter system was very small over-shoot in the transient state while the error voltage at steady state was equal to zero. In Fig. 8-b., the voltage error signal of the closed-loop buck converter controller system was a small value in the transient and it has become zero at the steady state. In Fig. 8-c., the action response of the digital PID controller was smooth without oscillation response, no spikes behavior and the action did not reach to the saturation state of 3.7 volt depending on the supply voltage. Fig. 8-d. clearly shows the improved performance index of the buck converter system related with the MSE for the off-line tuning PSO control methodology.

(a)

(b)
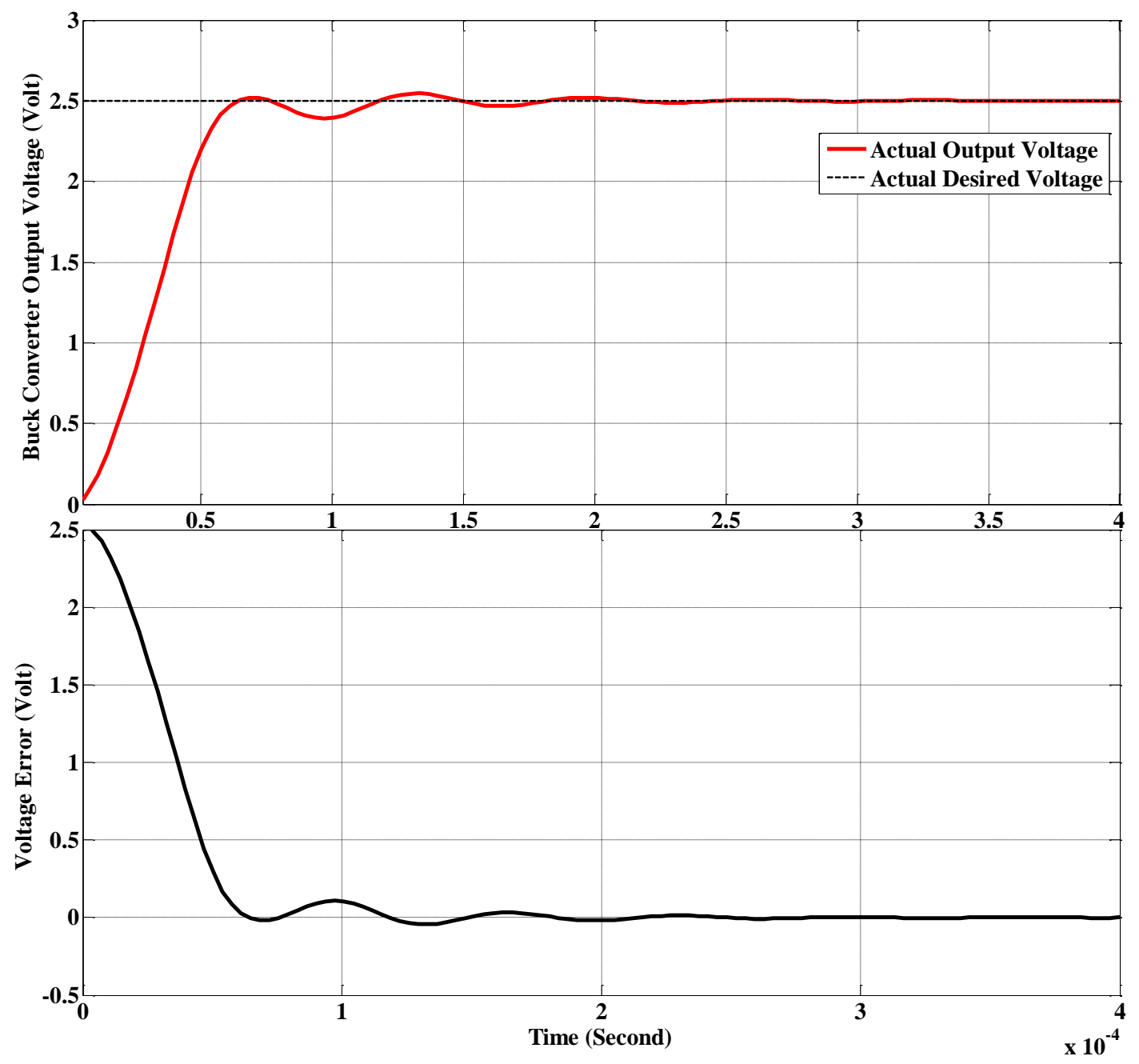
(c)

(d)

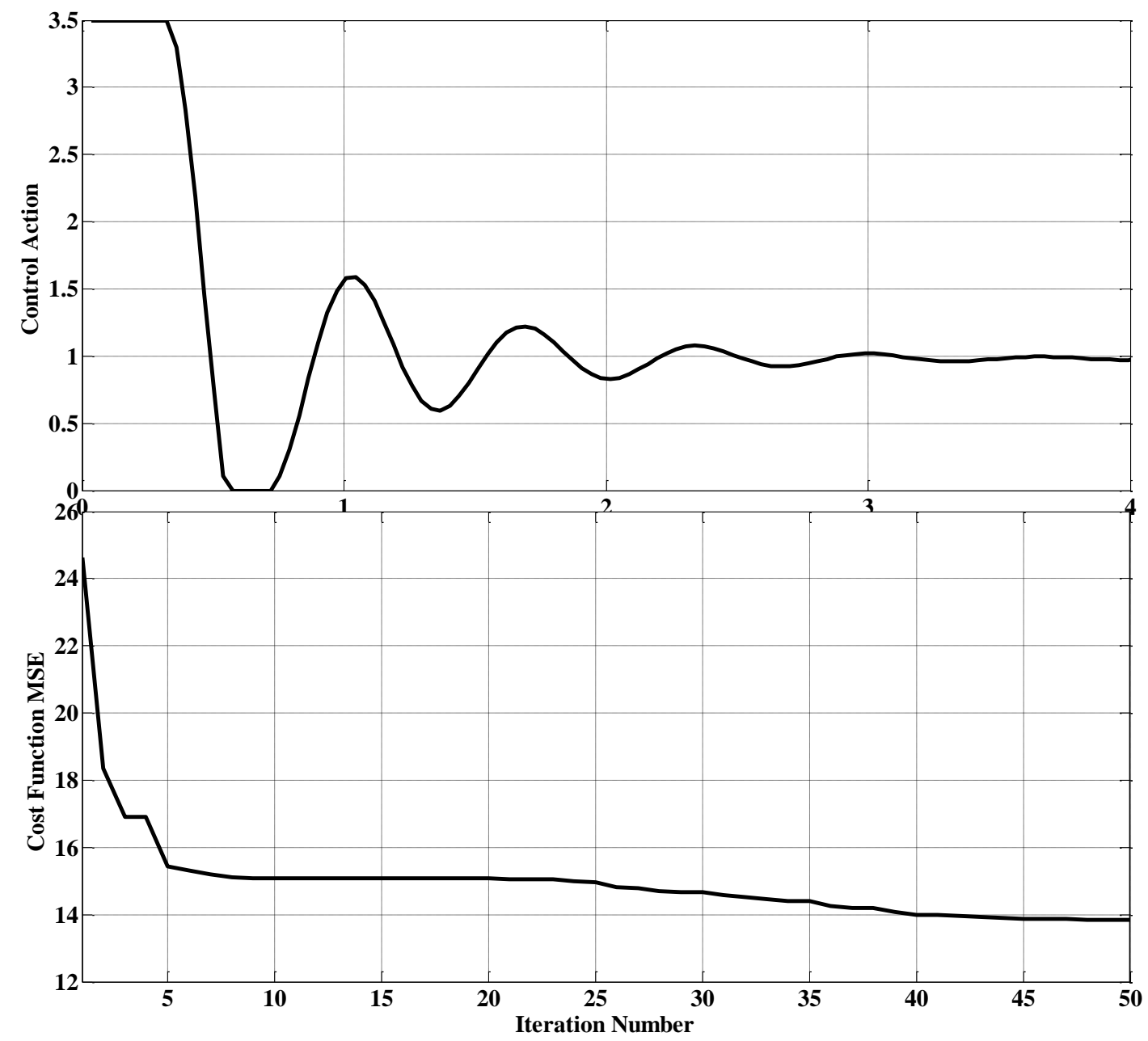

Fig. 8. THE Digital SISO-PID CONTROLLER NUMERICAL SimUlation RESUltS WHEN Wi-Fi APPLICATION TURN ON (A) BUCK CONVERTER ACTUAL AND DESIRED OUTPUT VOLTAGE ; (B) SignAL ERROR; (C) SignAL CONTROL OPERATION; (D) OFF-LINE

\section{Case III} PERFORMANCE INDEX (MSE).

To investigate the proposed SISO-PID controller has high robustness performance during load current variation by using many applications in the same time. BT application turns on at $(0.403 \mathrm{msec})$ in the smartphone in addition Wi-Fi application was turned on. Based on off-line PSO algorithm parameters, after finishing 50 iterations the best control gains parameters are obtained as $\mathrm{kp}=12.9689, \mathrm{ki}=3.0456$ and $\mathrm{kd}=2.4846$.

As shown in Fig. 9-a. the output voltage response of the Buck converter system at $(0.445 \mathrm{msec})$ was very small over-shoot and very small oscillation but the error voltage at steady-state was equal to zero.

In Fig. 9-b. the error voltage level between the actual and desired output voltage of the buck converter system at transient and steady states is small value, the error voltage became very nearby to zero and very small oscillation.

Fig. 9-c. illustrates the response of the control operation which has a fast and powerful adaptability with high performance of robustness because the control parameters are learned off-line PSO algorithm especially when turning on BT application (adding boundary disturbance) to show that the control operation has an ability to track the error signal of the buck converter system in order to follow the reference voltage as step change and minimize the disturbance effect of the load resistance.

Fig. 9-d. shows that the cost function of the off-line tuning PSO control algorithm is distinctly enhanced the behavior and performance of the proposed digital PID controller for the buck converter system 
especially at time $(0.4 \mathrm{msec})$ during adding disturbance (turn on BT application) then difference equation of buck converter model for BT applications can be represented in (20).

$v_{o}(k)=0.02087 u(k-1)-0.007441 u(k-2)+1.82 v_{o}(k-1)-0.8263 v_{o}(k-2)$

(a)

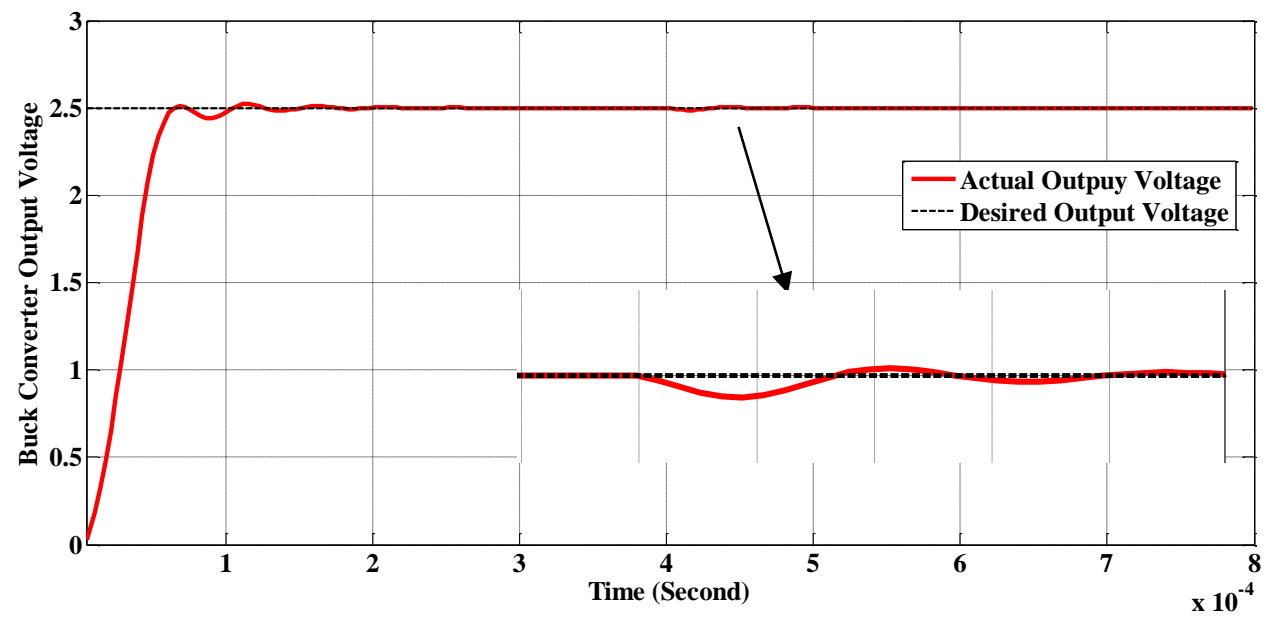

(b)

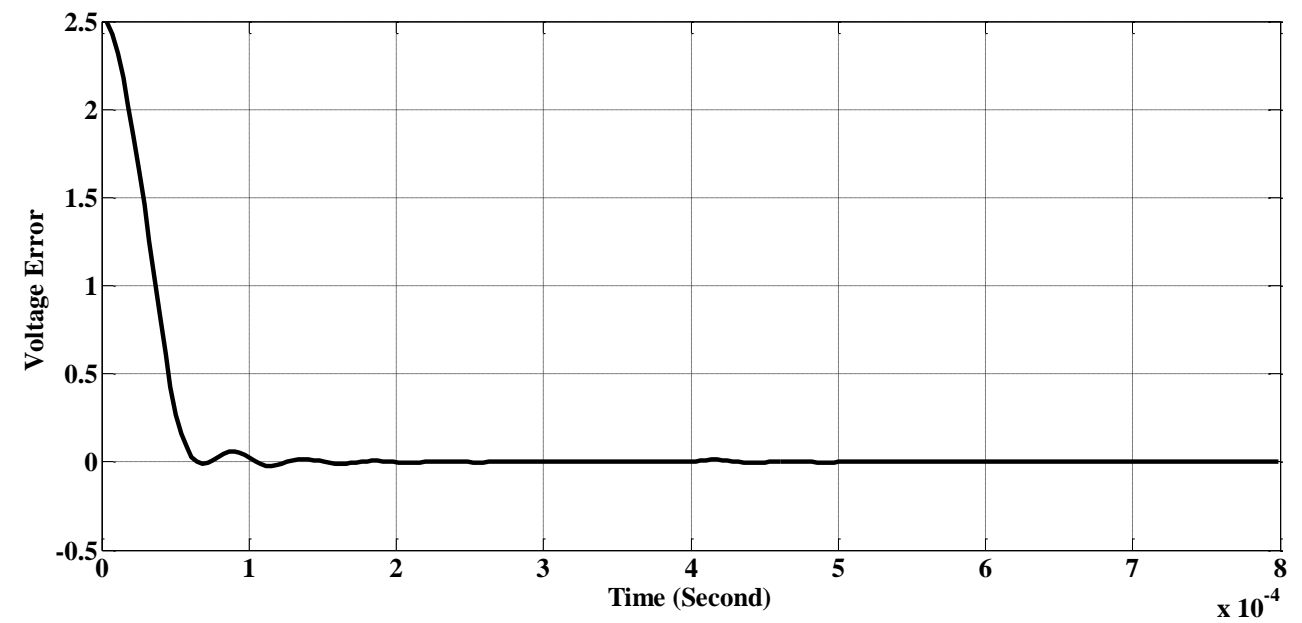

(c)

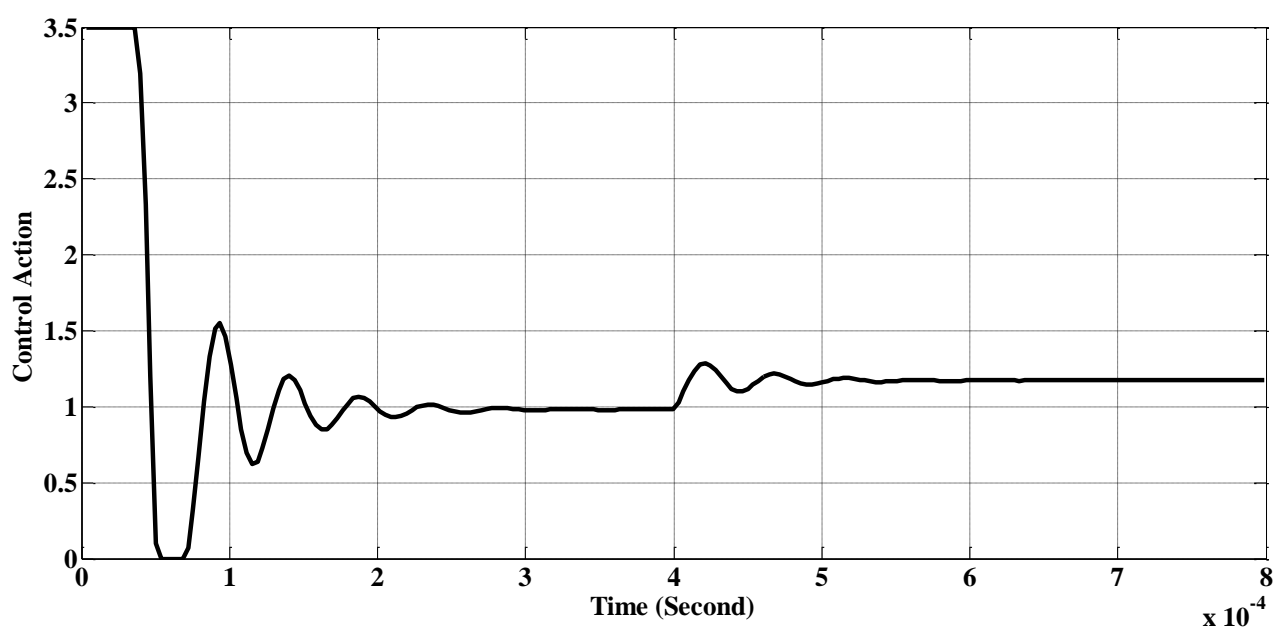


(d)

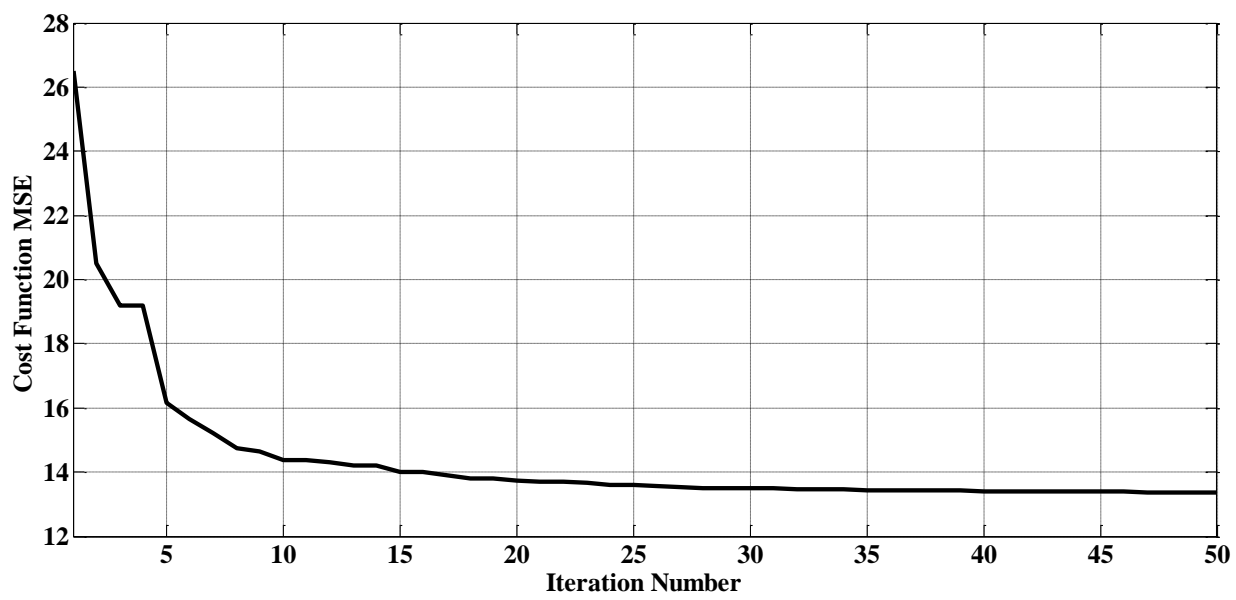

Fig. 9. THE DIGITAL SISO-PID CONTROLLER NUMERICAL SiMULATION RESULTS WHEN Wi-Fi+BT APPLICATION TURN ON (A)

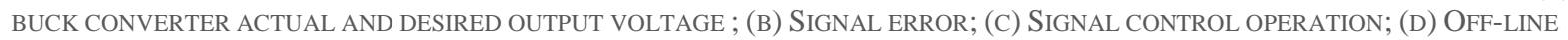
PERFORMANCE INDEX (MSE).

\section{EXPERIMENTAL WORK}

To carry out the proposed off-line SISO-FPGA-PID Verilog program controller, as shown in Fig. 3. MATLAB environment system uses the real-time Spartan-3E Starter kit with device xc3s500e-4fg320 as shown in Fig. 10.

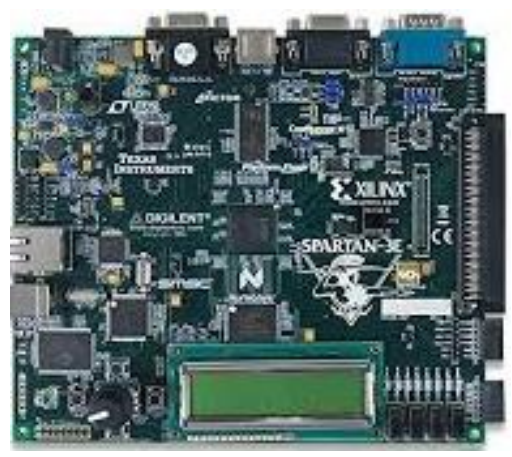

Fig. 10. SPARTAN -3E STARTER Kit.

The proposed controller Verilog program file is extracted to the black box using the Xillinx-system generator in the MATLAB environment. The black box with the ports Gateway In and Gateway Out are shown in Fig. 11.

It is tested with the overall buck converter system under MATLAB environment before downloading as shown in Fig. 12.

This black box is utilized for downloading the bit-stream of the proposed SISO-FPGA-PID Verilog program controller on the Spartan-3E Starter Kit with the device xc3s500e-4fg320 through the system generator by using the Joint-Test-Action-Group (JTAG) as an interface and by the universal serial bus (USB) cable. The hardware co-simulation mechanism is utilized to implement this downloading process and to build the hardware of the designed controller. Firstly, the used kit name is selected from the HDL netlist. At the beginning of generating a co-simulation block, a finishing status was demonstrated. The XFlow is done without errors after finishing processes of generating, performing, synthesizing, and running. After finishing these processes successfully, a JTAG block is generated, as illustrated in Fig. 13. 
FIG. 11.

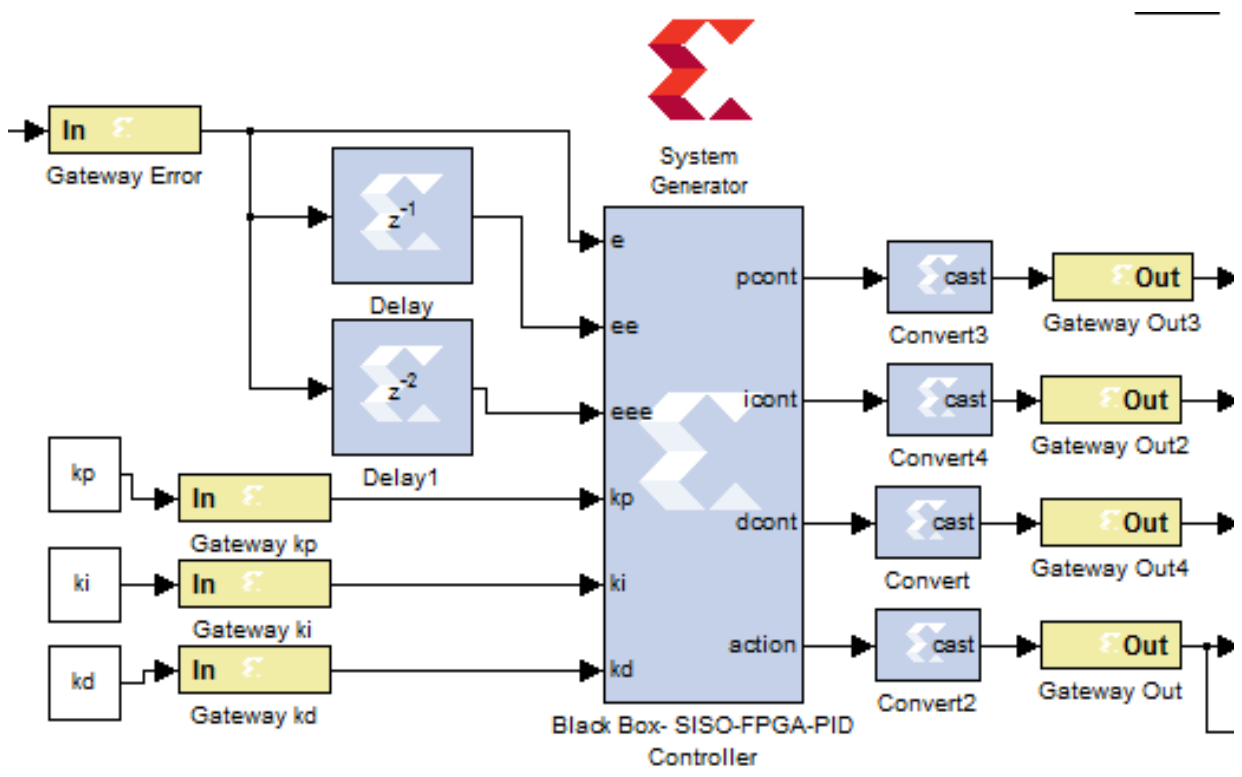

BOX WITH THE

GATEWAY IN AND GATEWAY OUT OF THE SISO-FPGA-PID CONTROLLER.

THE BLACK PORTS

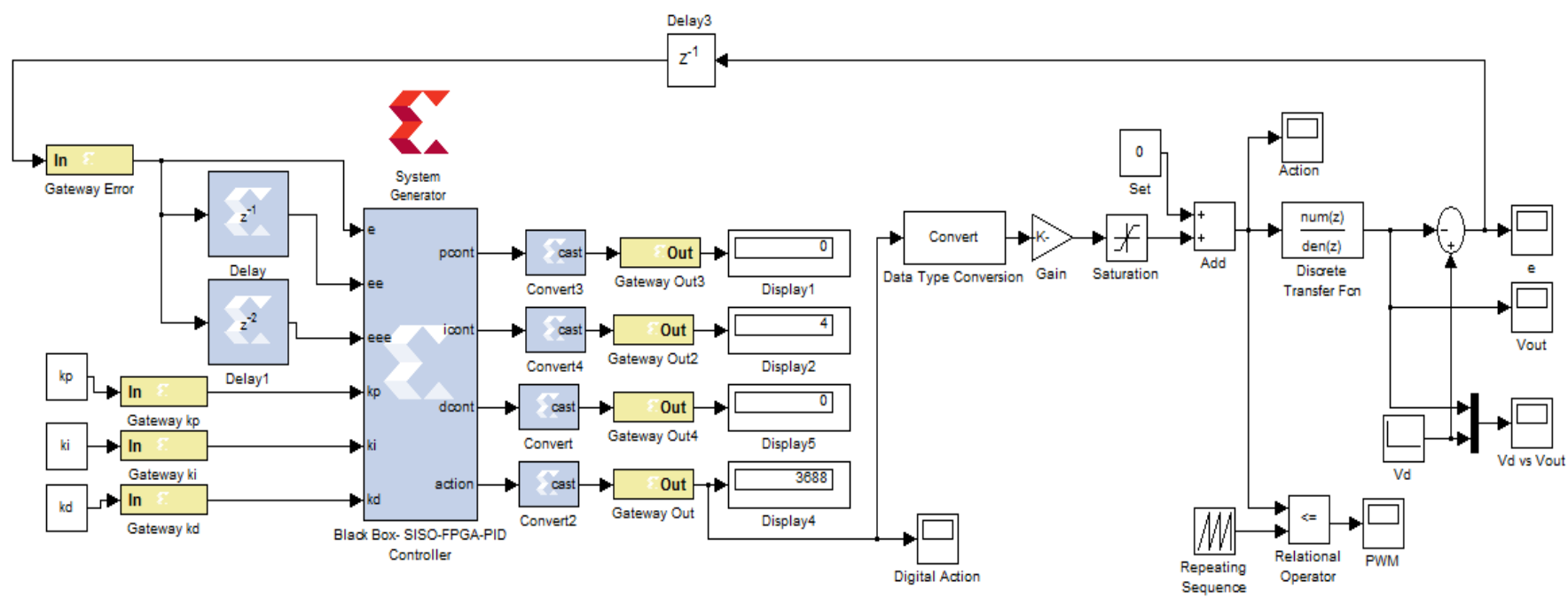

Fig. 12. THE OVERALL BUCK CONVERTER SYSTEM UNDER SISO-FPGA-PID CONTROLLER IN MATLAB ENVIRONMENT.

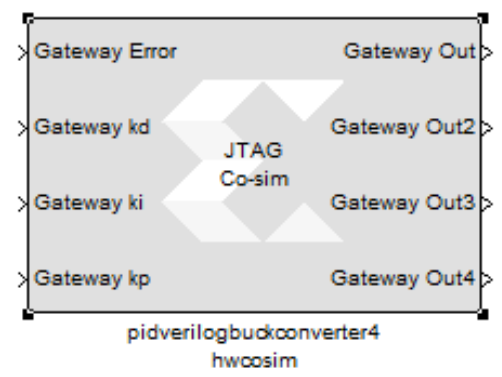

FIG. 13. JTAG BLOCK.

During the system simulation running, the interaction between the Spartan-3E Starter Kit and device xc3s500e-4fg320 by using the JTAG hwcosim (hardware co-simulation) interface block. The incoming data from the buck converter system is passed to the FPGA kit through the Gateway Ins, whereas the FPGA kit sends the control signal as output data to the buck converter system through the Gateway Out of the 
JTAG block. Hence, Figs. 14-a and b exhibit the block diagram of the proposed "SISO-FPGA-PID controller" for the buck converter system in the real-time.

In the real-time, Fig. 15-a. shows that the buck converter output voltage at transient state has a fast response with very small overshoots at desired voltage equal to 1.5 volt and the sampling time equal to $3.6 \mu \mathrm{sec}$ and at steady-state the voltage error of the system is equal to zero. Fig. 15-b. illustrates the high performance of digital SISO-FPGA-PID controller in terms of fast generating digital voltage control action that it has the ability to track desired voltage of the buck converter model. The PWM signal is generated as in Fig. 15-c. and in Fig. 15-d. that show the error voltage level between the required and actual buck converter output voltage system which it has small value at transient then at steady states the error signal became very nearby to zero.

(a)
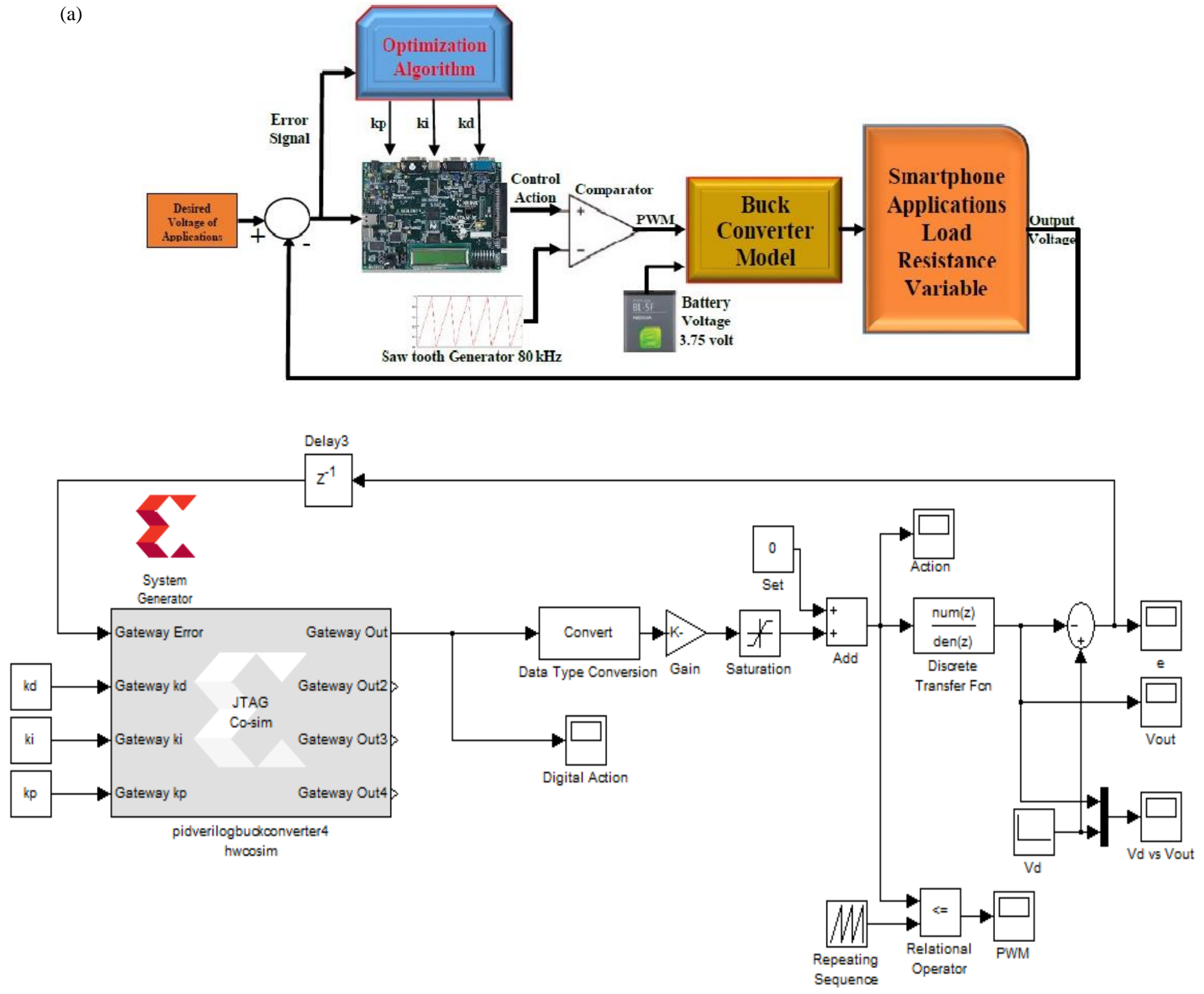

Fig. 14. (A) REAL-TIME PROPOSED SISO-FPGA-PID CONTROLLER BLOCK DIAGRAM; (B) SYSTEM GENERATOR IN THE MATLAB SIMULINK ENVIRONMENT. 


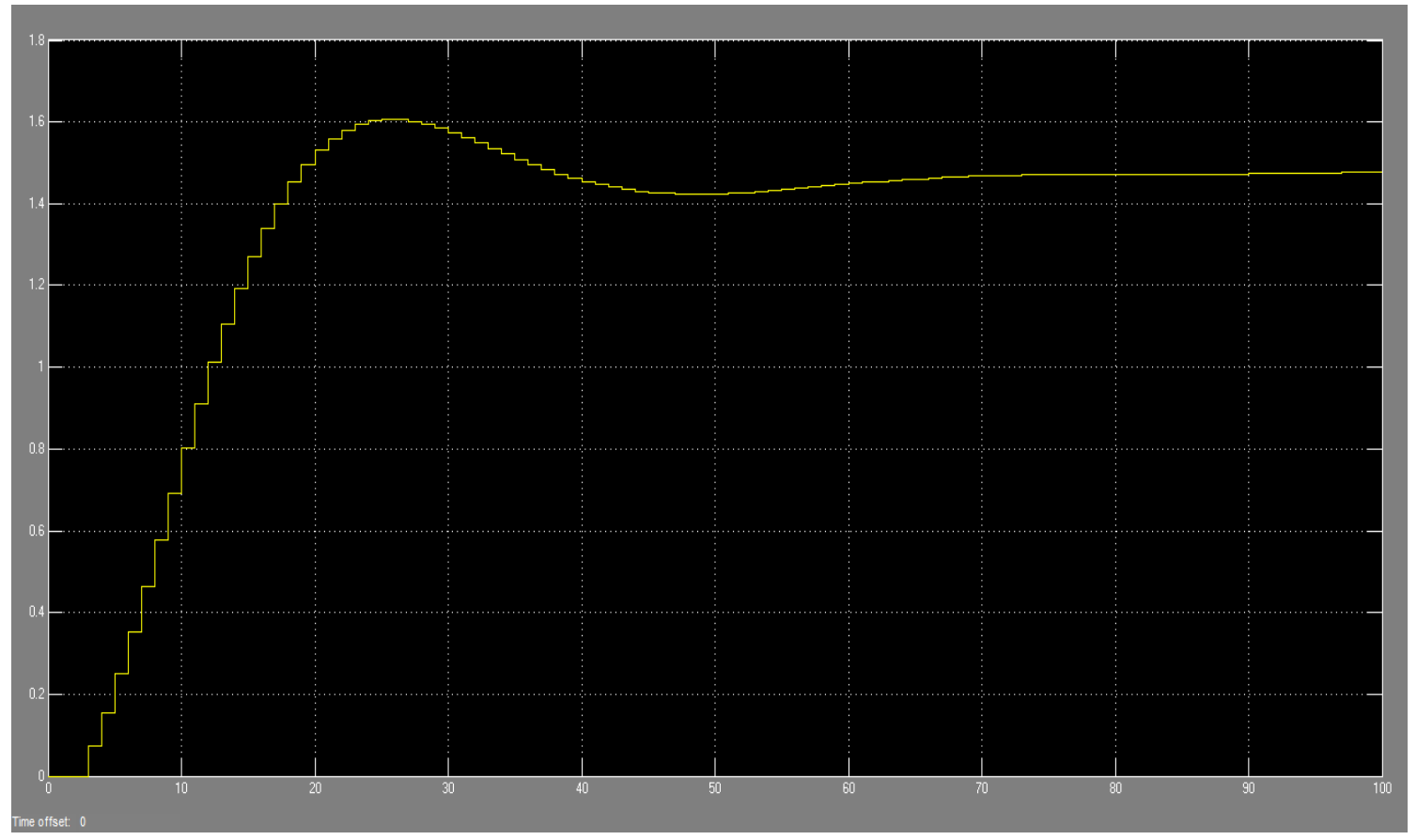

(a)

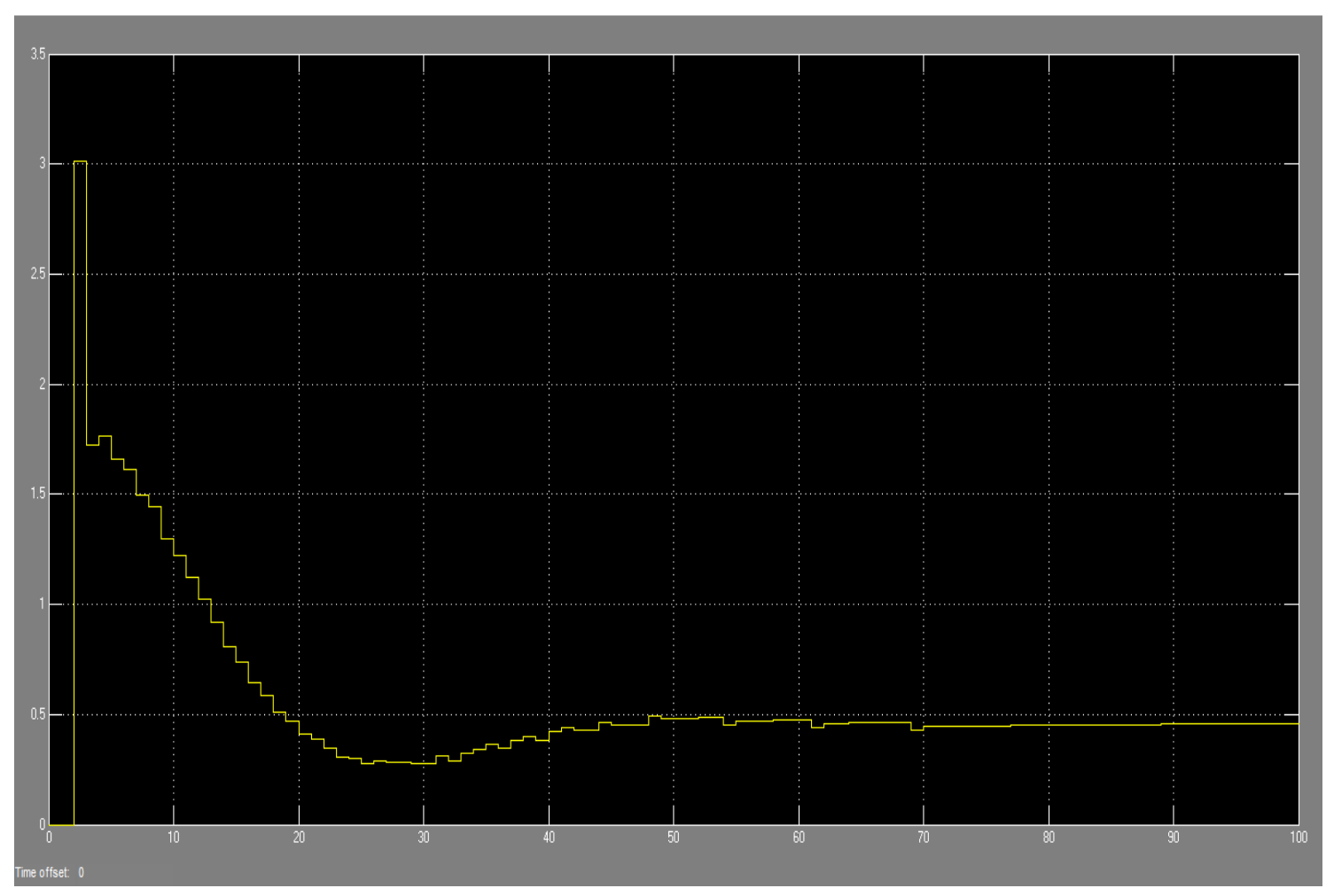

(b) 


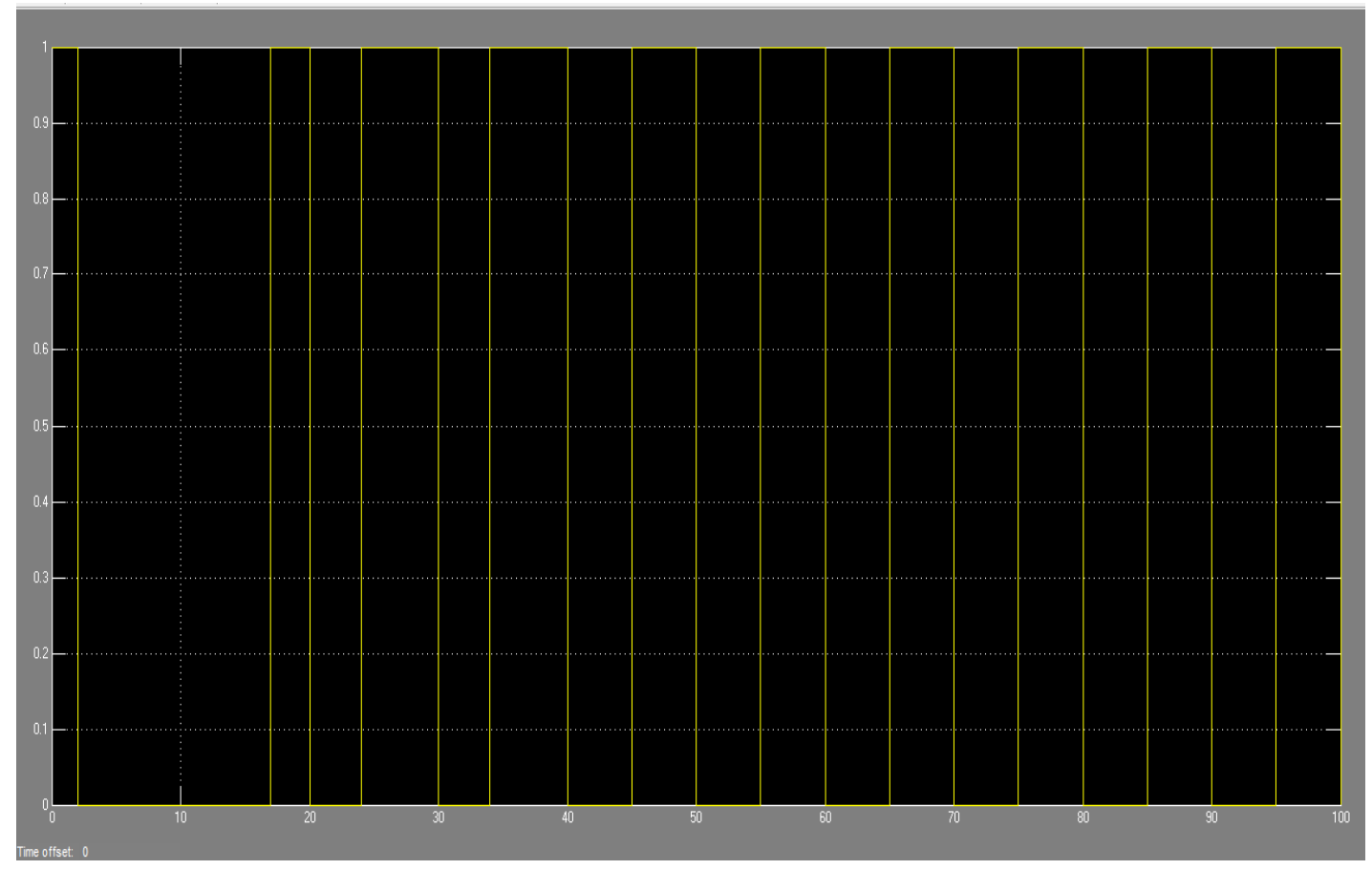

(c)

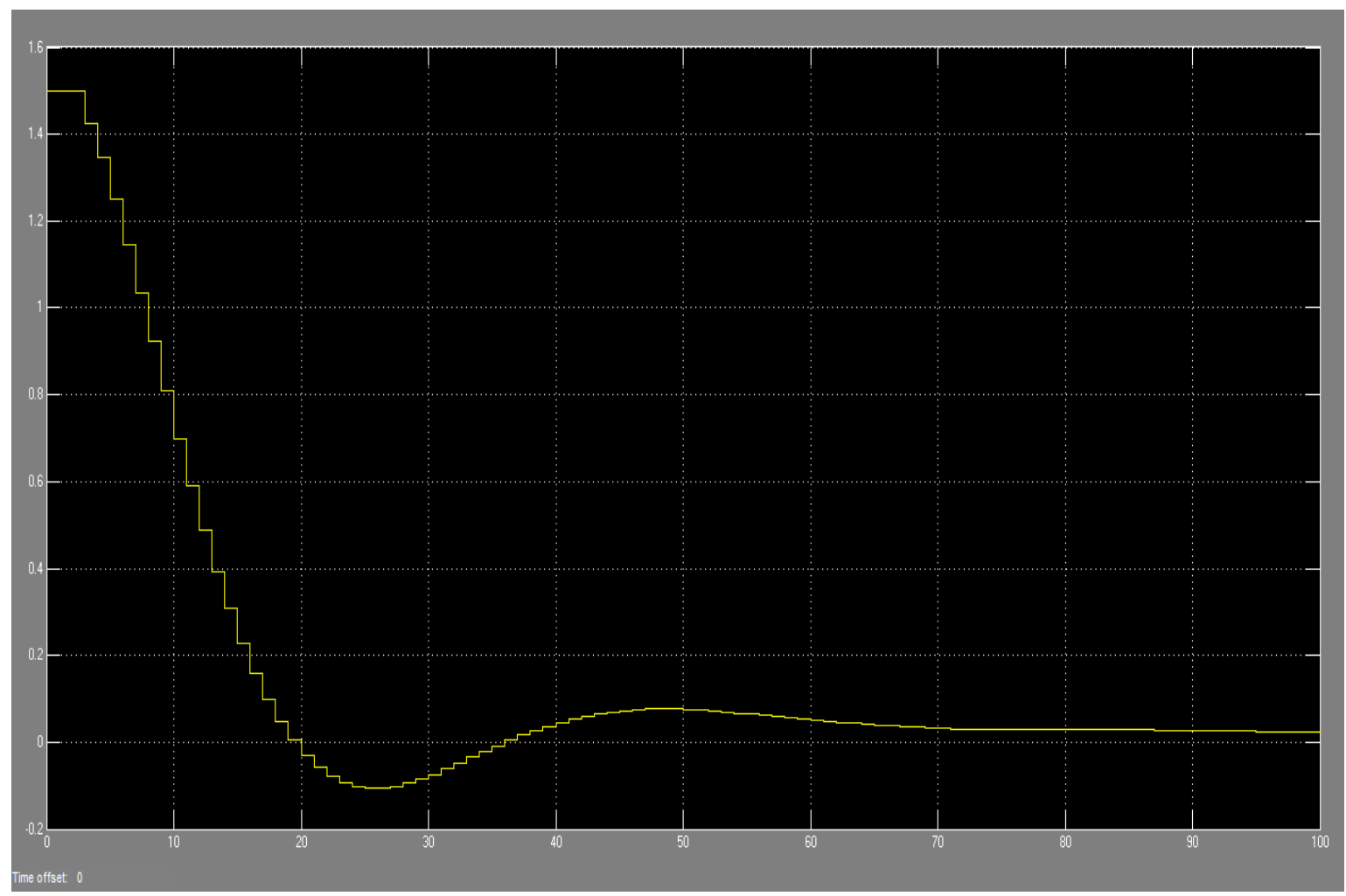

(d)

Fig. 15. The REAL-TIME RESPONSE (A) BUCK CONVERTER ACTUAL OUTPUT VOLTAGE; (B) DigitAl VOlTAGE CONTROL ACTION; (C) THE PWM SIGNAL; (D) THE ERROR VOLTAGE LEVEL. 


\section{CONCLUSIONS}

This paper presents a proposed digital SISO-FPGA-PID controller with the off-line PSO algorithm that can be used to control the linear dynamic behaviour of a buck converter model in order to keep the voltage level delivered in each smartphone applications, and results of numerical MATLAB simulations and experimental Spartan-3E board work show that:

- The off-line PSO is a fast learning algorithm that can be used to generate voltage control action without an oscillation response or a saturation state problem.

- A minimum fitness evaluation is required to determine the optimal weight parameters for the "SISOFPGA-PID controller".

- The strong robust SISO-FPGA-PID controller can track the output buck converter system to achieve the required voltage during using multi applications such as Wi-Fi, and BT at the same time.

\section{REFERENCES}

[1] Bicen, H. and Kocakoyun, S., "The Evaluation of the most Used Mobile Devices Applications by Students". The $2^{\text {nd }}$ Cyprus International Conference on Educational Research. pp. 756 - 760, 2013.

[2] Al-Araji, A., "Development of an On-Line Self-Tuning FPGA-PID-PWM Control Algorithm Design for DC-DC Buck Converter in Mobile Applications”. Journal of Engineering, Vol. 23, No. 8, pp. 84-106, 2017.

[3] Prathap, J. A. and Anandhi, T. S., "FPGA based Hybrid Digital PWM for DC-DC Voltage Regulator". Global Journal of Researches in Engineering, Vol. 17, No. 1, pp. 6-18, 2017.

[4] M. Sh. and Swaminathan, P., "Digital Linear and Nonlinear Controllers for Buck Converter". International Journal of Soft Computing and Engineering, Vol. 2, No.1, pp. 336-342, 2012.

[5] Gaouzi, K., EL-Fadil, H., Belhaj, F. Z., Rachid, A. and El-Idrissi, Z., "Predictive Control of DC-DC Buck Power Converters: Theoretical Analysis and Experimental Results". The $4^{\text {th }}$ International Conference on Automation Control Engineering and Computer Science (ACECS) proceedings of Engineering and Technology, Vol. 19, pp. 94-99, 2017.

[6] Garg, M. M., Hote, Y. V. and Pathak, M. K., "Design and Performance Analysis of a PWM DC-DC Buck Converter Using pi-Lead Compensator". Arabian Journal for Science and Engineering, Vol. 40, No. 12, pp. 3607-3626, 2015.

[7] Yusufzai1, S. K. and Pandey, P., "Design of a Hysteresis Controller for DC Buck Converter". International Journal for Research in Applied Science \& Engineering Technology (IJRASET), Vol. 5, No. 9, pp. 57-60, 2017.

[8] Roy, T. K., Mahmud, M. A., Shen, W., Haque, M. E. and Oo, A. M. T., "Robust Adaptive Back-stepping Controller Design for DC-DC Buck Converters with External Disturbances”. IEEE 11th Conference on Industrial Electronics and Applications (ICIEA), pp. 1218-1223, 2016.

[9] Swamy, K. N., Prithvi, P. H. and Chakravarthi, N. S. K., "Design Buck Converter Using Fuzzy Logic Controller”. International Journal for Modern Trends in Science and Technology, Vol. 05, No. 10, pp. 1-5, 2019.

[10] Taheri, B., Sedaghat, M., Bagherpour, M. A. and Farhadi, P., "A New Controller for DC-DC Converters based on Sliding Mode Control Techniques”. Journal of Control Automation and Electrical Systems, DOI: 10.1007/s40313-018-00427-w, 2018.

[11] Gupta, M. and Phulambrikar, P., "Design and Analysis of Buck Converter”. International Journal of Engineering Research \& Technology, Vol. 3, No. 3, pp. 2346-2350, 2014.

[12] Siddhartha, V., Hote, Y. V. and Saxena, S., "Non-ideal Modeling and IMC based PID Controller Design of PWM DC-DC Buck Converter". Conference of International Federation of Automatic Control, pp. 639-644, 2018.

[13] A. Al-Araji, "Applying Cognitive Methodology in Designing On-Line Auto-Tuning Robust PID Controller for the Real Heating System”. Journal of Engineering, Vol. 20, No. 9, pp. 43-61, 2014.

[14] A. Al-Araji, "Genetic Algorithm and Elman Neural Network used for Tuning the Parameters of the PID Neural Controller based Model Reference". Iraqi Journal of Computer, Communication, Control and Systems Engineering, Vol. 5, No. 1, pp. 111-126, 2005.

[15] Sravanthi, G. and kumar, N. R., "PID Controller Implementation for Speed Control Applications using FPGA". International Journal of VLSI System Design and Communication Systems, Vol. 2, No. 6, pp. 364-370, 2014.

[16] Valle, Y. D., Venayagamoorthy, G. K., Mohagheghi, S., Hernandez, J.C. and Harley, R. G., "Particle Swarm Optimization: basic Concepts, Variants and Applications in Power Systems". IEEE Transactions on Evolutionary Computation, Vol. 12, No. 2, pp. 171-195, 2008.

[17] A. Al-Araji, "Design of On-Line Nonlinear Kinematic Trajectory Tracking Controller for Mobile Robot based on Optimal Back-Stepping Technique”. Iraqi Journal of Computers, Communication and Control \& Systems Engineering, Vol. 14, No. 2, pp. 25-36, 2014. 
[18] Dagher, K. E., "Modified ELMAN neural-PID Controller Design for DC-DC Buck Converter System based on Dolphin Echolocation Optimization". Al-Khwarizmi Engineering Journal, Vol. 14, No. 3, pp. 129- 140, 2018.

[19] Perrucci, G. P., Fitzek, F. H. P. and Widmer, J., "Survey on Energy Consumption Entities on the Smartphone Platform". IEEE 73rd Vehicular Technology Conference (VTC Spring), Yokohama, pp. 1-6, 2011.

[20] Tapou, M. S., Al-Raweshidy, H. S., Abbod, M. and Al-Kindi, M. J., "A Buck Converter for DVS Compatible Processors in Mobile Computing Applications using Fuzzy Logic Implemented in a RISC based Microcontroller". The $2^{\text {nd }}$ International Conference on Circuit and System Control Signal. Prague, Czech. pp. 135-139, 2011. 